\title{
An Overview of Nuclear vs. Non-Nuclear Design Code Requirements for a Candidate Steam Supply System for Commercial Applications
}

Robert Jetter

April 2011

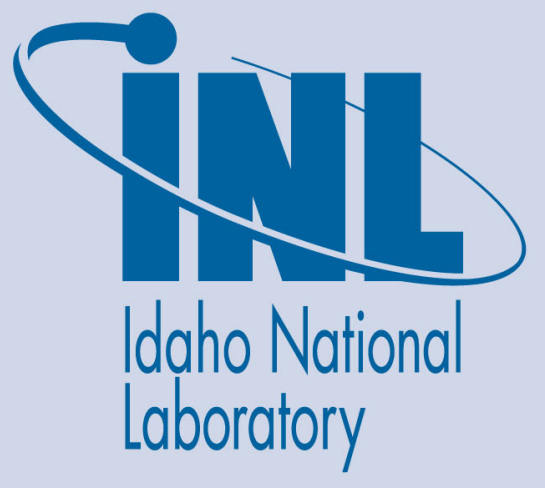

The INL is a U.S. Department of Energy National Laboratory operated by Battelle Energy Alliance 
INL/EXT-11-22715

\section{An Overview of Nuclear v. Non-Nuclear Design Code Requirements for a Candidate Steam Supply System for Commercial Applications}

Robert Jetter

April 2011

Idaho National Laboratory
Idaho Falls, Idaho 83415

http://www.inl.gov

Prepared for the

U.S. Department of Energy

Office of Nuclear Energy

Under DOE Idaho Operations Office

Contract DE-AC07-05ID14517 


\title{
An Overview of Nuclear vs. Non-Nuclear Design Code Requirements for a Candidate Steam Supply System for Commercial Applications
}

\author{
Report \\ by \\ Robert Jetter \\ $3 / 29 / 2011$ \\ Revised 4/2/2011 \\ Prepared for \\ Battelle Energy Alliance, LLC(BEA) \\ Idaho National Laboratory \\ Under
}

Amendment No.2 to Contract No. 102738

Submitted to

M. W. Patterson

Project Manager,

NGNP Process Heat Applications

Robert Jetter, Consultant

1106 Wildcat Canyon Rd.

Pebble Beach, CA 93953

better@sbcglobal.net 
INL/EXT-11-22715

\section{Introduction:}

The objective is to identify (mostly for industrial end-users) the difference between a Section III nuclear steam generator (classified as Structures, Systems and Components (SSC)) and a Section VIII steam generator in the same general conditions, but used in a conventional application. Specifically, applicable temperature and pressure ranges and a more quantitative description of how materials change, design margins change and required design rigor changes are of interest. This overview focuses on the steam generator pressure boundary but the downstream piping will also be considered.

Within the designations of Section III and Section VIII there are subcategories with their specific regions of applicability. Each of these subcategories has evolved their own unique features with respect to design rules and their implementation. A general overview of the various design codes will be provided in sufficient detail to illustrate the major differences; however, a detailed discussion of the various design requirements and their implementation is beyond the scope of this discussion. References (1) and (2) are sources of more detailed information. Also, example wall sizing calculations will be provided to illustrate the application of the relevant design codes under the candidate design conditions. The candidate steam supply Design Conditions are $600 \mathrm{C}(1112 \mathrm{~F})$ and $24 \mathrm{MPa}(3,480 \mathrm{psi})$. The Operating Conditions or Service Levels will be somewhat lower and the difference shows up in some of the various design methodologies employed.

\section{Discussion}

\section{Section III}

Section III covers all phases of construction; materials, design, fabrication and installation, examination, testing, over pressure protection, and name plates, stamping and reports. (Section VIII does likewise but in a different format). Importantly, Section III also covers a wide range of components: vessels, pumps, valves and piping are those of direct interest to this discussion. Section III also provides rules for different classes of components depending upon their safety significance. Class 1 is the highest level followed by Class 2 and 3. (Note: In the new Section III, Div 5 for high temperature reactors, Class 1 corresponds to Class A and Class 2 corresponds to Class B.) Selection of the appropriate classification for specific components is beyond the scope of Section III. However, in the case of the steam generator, if the He gas side is primary system reactor coolant, the $\mathrm{He} / \mathrm{H}_{2} \mathrm{O}$ interface would normally be considered Class 1 . If the $\mathrm{He}$ side is from an $\mathrm{IHX}$, then the $\mathrm{He} / \mathrm{H}_{2} \mathrm{O}$ interface might be considered Class 2.

At temperatures below the creep range, the rules for Class 1 construction are in Subsection NB; for Class 2 they are in Subsection NC. At elevated temperatures where creep is (or might be) significant, the rules for Class 1 construction, including vessels, pumps, valves and piping, are in Subsection $\mathrm{NH}$. For Class 2 materials and design the elevated temperature rules are in Code Case N-253. The rules for other phases of construction are in other code cases. The upper temperature limit for Subsection NB and NC is $700 \mathrm{~F}(371 \mathrm{C})$ for ferritic materials such as $2.25 \mathrm{Cr}-1 \mathrm{Mo}$ and $800 \mathrm{~F}(427 \mathrm{C})$ for austenitic materials such as 316SS. Above these temperatures Subsection NH applies for Class 1 components and Code Case N-253 applies for Class 2 and 3 components.

The allowable stress values, $S_{m}$, for NB are in Table 2 of Section II, Part D of the ASME B\&PV Code. The allowable stresses for NC are in Table 1, The allowable stresses for Section VIII, Div 1 are also in Table 1 
and are the same as those for NC up to the 700/800F limit for NC. The allowable stresses for NH are in a $\mathrm{NH}$ appendix and the allowable stresses for $\mathrm{CC} \mathrm{N-253}$ are in an appendix of that code case, which also references Table 1 in Section II. There are many material choices for Subsection NB construction.

The criteria for Section III, Class I allowable stresses below the 700/800F boundary in Table 2, $\mathrm{S}_{\mathrm{m}}$, are the lower of $2 / 3$ of the minimum yield strength ${ }^{(1)}$ and (1.1)/3 of the tensile strength. The criteria for Section III, Class 2 and Section VIII, Div 1 allowable stresses in Table 1 are the lower of 2/3 of the minimum yield strength and (1.1)/3.5 of the tensile strength. This means that VIII, Div 1 is more conservative below the creep range than a Section III, Class 1 component where the allowable stress is governed by the criterion for tensile strength. The situation is different in the creep range.

For temperatures above the 700/800F boundary, for Class 1 components there are additional allowable stresses defined by Subsection $\mathrm{NH}$. $\mathrm{S}_{\mathrm{o}}$ is the allowable stress for Design Conditions and is intended to be identical to the allowable stress for Section VIII, Div 1 designs. The criteria for $\mathrm{S}_{\mathrm{o}}$ will be discussed under Section VIII but a key point is that when creep properties govern, it is based on creep properties at $100,000 \mathrm{hr}$. NH also defines other allowable stress parameters for the evaluation of Service Levels. These are $S_{m}, S_{t}$, and $S_{m t}$. The criteria for $S_{m}$ are the same as below 700/800F, e.g. 2/3 yield and (1.1)/3 tensile. These are referred to as time independent allowable stresses. The criteria for $S_{t}$ are the lesser of $2 / 3$ the minimum creep rupture strength in time, $\mathrm{t} ; 80 \%$ of the minimum stress to cause third stage creep in time, $\mathrm{t}$; and $100 \%$ of the stress for $1 \%$ strain in time, $t$, where $t$ is the time duration of the loading condition under consideration. These are referred to as time dependent criteria. $S_{m t}$ is the lower of $S_{m}$ or $S_{t}$. Thus there is an important difference between $\mathrm{NH}$ allowable stresses which are a function of the load duration and VIII, Div1 allowable stress which are based on properties at 100,000 hours. However, it gets yet more complicated.

The required wall thickness in $\mathrm{NH}$ is determined for both Service Level conditions and Design Conditions and the thickest requirement governs. Thus, if Design Condition requirements govern, the wall thickness will be the same under either Section VIII Div 1 or Section III Subsection NH. Without getting into all the details, generally, the wall thickness requirements for Section VIII, Div 1, Section III Subsection NC and Code Case N-253 will also be the same. However, if Service Level conditions are more critical for NH components than Design Conditions, then the required wall thickness will be greater than for Section VIII Div 1 vessels. This would generally occur for long service lives at high temperatures.

An important point for Section III, Class 1 vessels is that the rules are based on design-by-analysis. That means that the designer is required to conduct a stress analysis to identify all critical areas. It is also a general requirement that this analysis will consider cyclic life and meet the requirements for fatigue life, or creep-fatigue life at local stress concentrations. This is a major increase in design effort and particularly so for elevated temperature $\mathrm{NH}$ components where the design rules are more complex due to the additional failure modes considered as opposed to the lower temperature NB rules, applicable below the creep regime. Because of these additional complexities it is much more involved to get approval of materials for Subsection NH construction. The only currently approved base materials are 304 and 316SS, Alloy 800H, 2.25Cr-1Mo Grade 22 Class1, and 9Cr-1Mo-V Grade 91.

(1) For some low yield strength materials, the allowable stress for applications where deformation is not critical is given by $90 \%$ of the minimum yield strength 


\section{Section VIII}

There are three divisions of Section VIII, Div 1, Div 2 and Div 3. Section VIII, Div 1 is the classical, long standing code used for vessels which neither fall under the auspices of Section III nor fired power boilers covered in Section I. (Note: Although there are differences in design rules, the allowable stress values for Section I and Section VIII, Div 1 are the same.) Section VIII, Div 1 covers all aspects of construction but only applies to vessels. A steam generator which does not generate steam by exposure to a flame would fall under Section VIII. Many Section VIII vessels, mostly Div 1, are used in the petro-chemical industry. However, there is increasing use of Div 2 to take advantage of the higher allowable stress values for some materials.

Section VIII Div 1 covers the temperature range from cryogenic to very high creep temperatures. The VIII Div 1 design approach is referred to as design-by-rule wherein formulas are provided to calculate required wall thicknesses based on the allowable stress, loading and pertinent geometric parameters for the particular shape under consideration. For example, for a simple cylindrical shell the parameters would be a diameter, applied pressure and allowable stress and the result would be the required thickness. Rules are not provided in VIII Div 1 to assess cyclic life and fatigue although the permitted design details are such that for many configuration fatigue will not be critical for modest cyclic service.

As noted above, the allowable stress criteria for Section VIII Div 1 are the same as for those in the nuclear code Section III, Subsection NC, below 700/800F and they are equal to or more conservative than the allowable stress criteria for Class 1 , Subsection NB components below the creep regime. In the creep regime, the allowable stress criteria for Section VIII Div 1 is the lesser of $2 / 3$ of the average ${ }^{(1)}$ or $80 \%$ of the minimum creep rupture strength in $100,000 \mathrm{hr}$ or $100 \%$ of the average stress to produce a creep rate of $0.01 \% / 1000 \mathrm{hr}$. Nominally, for many materials, it is the minimum creep rupture strength that governs the allowable stress in the creep regime. Thus, at 100,000 hours, the allowable stress in NH will be a factor of $(2 / 3) /(0.8)$ or 0.83 lower than the corresponding allowable stress in VIII Div1. However, this difference is tempered by the observation that the VIII, Div 1 allowable stress is applied to Design conditions while the $\mathrm{NH}$ allowable stress is applied to the lower Service Level conditions.

Section VIII Div 2 more closely lines up with Section III, Subsection NB for Class 1 components although Div 2 only covers vessels. Div 2 provides two routes for design; design-by-analysis similar to Subsection NB and design by rule, similar to Div 1; however, even when using the design-by-rule procedures, the fatigue life must be considered explicitly. This can be accomplished by using the design-by-analysis rules or by meeting certain screening criteria for exemption from detailed fatigue analysis. Implementation of the detailed fatigue life evaluation approach in the design-by-analysis is limited to $700 / 800 \mathrm{~F}$ the same as Subsection NB. However, the screening criteria are applicable above this temperature. Again, however, there is a further limitation on the screening criteria. Above the transition temperature where the allowable stresses are governed by time dependent creep properties, the only acceptable screen criteria is that one which requires experience with similar equipment in similar service; thus, effectively ruling out new designs for new applications. All the currently approved materials for Div 2 have transition temperatures below $1112 \mathrm{~F}$. However, for vessels constructed of materials whose transition temperature is above the operating temperature there is a window of opportunity provided by the allowable stress criteria for Section VIII, Div2.

(1) The average value of the creep rupture strength is obtained from a best fit model correlation of the data 
In Section VIII, Div 2, the allowable stress criteria below the creep regime are given by the lesser of 2/3 of the minimum yield strength or $1 /(2.4)$ of the tensile strength. This means that for high yield strength materials the allowable stress will be greater for VIII Div 2 applications than for the same material in either VIII Div 1 or Section III applications. For example, for Grade 91 steel at $900 \mathrm{~F}$, the allowable stress for Div 2 is $30.8 \mathrm{ksi}$, for Div 1 it is $20.3 \mathrm{ksi}$ and for $\mathrm{NH}$ at $100,000 \mathrm{hr}$ it is $22.3 \mathrm{ksi}$. Above the transition temperature, in the creep regime, the allowable stress criteria for Div 2 are the same as Div1. The rationale for the higher allowable stress criteria in VIII, Div 2 below the creep regime is that there is a specific requirement for cyclic life evaluation whereas there is not for Section VIII, Div1 where the allowable stresses are lower for high yield strength materials.

Section VIII, Div 3 is specifically for very high pressure service. A key feature of Div 3 is that the allowable stress is limited to $2 / 3$ of the yield strength without any limit on the tensile strength. However, except as discussed below, the maximum design temperature is limited to the traditional 700/800F or lower. The exception is A-286 which is limited to 900F for Section VIII, Div 3 construction. Interestingly, A-286 is limited to 700F for Section VIII, Div 1 construction. Section VIII, Div 3 also requires a fatigue or a fracture mechanics evaluation depending upon a leak-before-break evaluation. Because of its very high strength characteristics, A-286 might have advantages for high pressure applications at $600 \mathrm{C}(1112 \mathrm{~F})$ but would require code committee approval.

\section{B31.3, NB, NC, NH and Code Case N-253 Piping Rules}

B31.3 is the piping equivalent of Section VIII, Div 1. The allowable stresses are the same in the creep regime and slightly more conservative below that (1/3.0 vs. (1.1)/3.5 times the tensile strength). The temperature range is about the same and the pressure range is somewhat higher. The wall thickness is based on standard pressure/temperature ratings for components or by design equations. Evaluation of restrained thermal expansion stress is based on cyclic testing of representative components by Markl in the 1950s and similar type testing in later years. Local thermal stress gradients are not considered. Subsection NB also considers the use of pressure temperature ratings but the restrained thermal expansion analysis, which also includes local thermal stresses, is based on direct analytical procedures and the use of fatigue life design curves. NC permits either the test based Markl approach or the analysis based NB approach. In either case the allowable stresses are given in Table 1 of Part D of Section II, the same as for VIII Div 1. NH piping design rules are based on the same criteria and allowable stresses as the other components in $\mathrm{NH}$. Code Case $\mathrm{N}-253$ is somewhat of a hybrid. The rules for restrained thermal expansion in the creep regime are based on Markl type testing but are very conservatively derated to account for creep. Also, the effects of local thermal gradients are included.

Although there are many acceptable materials listed in B31.3 with their corresponding allowable stress values, there are also provisions for the use of unlisted materials; an option which is not permitted in the vessel codes. As described by Becht in Chapter 17 of Ref (2), the use of Section VIII, Div 1 approved materials and their corresponding allowable stresses for B31.3 construction appears to be relatively straight forward. 
INL/EXT-11-22715

\section{Examples}

In this example, a required vessel wall thickness is calculated for three materials: $2.25 \mathrm{Cr}-1 \mathrm{M0}$, Alloy $800 \mathrm{H}$ and 617. The calculated thicknesses are based on Section VIII, Div 1 and Section III, Subsection NH. Since 617 isn't an approved NH material (but efforts are under way to get it approved) the earlier draft code case is used to "guesstimate" the allowable stress. The Design Condition is $1112 \mathrm{~F}(600 \mathrm{C})$ and $3,480 \mathrm{psi}(24 \mathrm{MPa})$. The somewhat lower Service Level A conditions are assumed to be $1067 \mathrm{~F}(575 \mathrm{C})$ and $3300 \mathrm{psi}(22.7 \mathrm{MPa})$ at $300,000 \mathrm{hr}$.

The required thickness for a cylindrical vessel will be based on the approximate formula:

$$
\begin{aligned}
t=\operatorname{pr}_{\mathrm{m}} / \mathrm{S} \text { where } \mathrm{t} & =\text { thickness } \\
\mathrm{p} & =\text { pressure } \\
\mathrm{r}_{\mathrm{m}} & =\text { mean radius } \\
\mathrm{S} & =\text { allowable stress }
\end{aligned}
$$

The assumed mean radius is $40 \mathrm{in}$.

The applicable allowable stresses and resultant wall thicknesses are given below. As noted above, in some cases the allowable stress is based on the $90 \%$ yield criterion for applications where deformation is not critical.

$$
\begin{gathered}
\text { Section VIII Div } 1 \\
\text { Design Conditions (1112F/3480psi) }
\end{gathered}
$$

(ksi/inches)

$$
2,25 \mathrm{Cr}-1 \mathrm{Mo}
$$

Alloy $800 \mathrm{H}$

617
$3.5 / 40.0$

11.0/12.6

20.8/6.7
Section III Subsection NH

Service Level A (1067F/3300psi)

(ksi/inches)

$4.2 / 31.4$

$11.9 / 11.1$

?18/7.3?

The above tabulation clearly shows that $2.25 \mathrm{Cr}-1 \mathrm{Mo}$ is not a viable material at this temperature and pressure and Alloy $800 \mathrm{H}$ is somewhat marginal for this diameter vessel. The required wall thickness is a function of both temperature and pressure; however, the allowable stress for $800 \mathrm{H}$ for Section VIII, Div 1 construction, even below the creep regime, only reaches $16.7 \mathrm{ksi}$ as compared to the allowable stress for 617 of $20.8 \mathrm{ksi}$ at $1112 \mathrm{~F}(600 \mathrm{C})$. Thus, there is a very clear incentive to have 617 approved for use in Subsection $\mathrm{NH}$ for such a high pressure, large diameter application. The tabulation also demonstrates that there is not a big difference between wall thickness requirements for Section VIII Div 1 construction and Section III Subsection NH. Even though the NH allowable stresses are lower at a given temperature,, they are compensated by the use of service condition operating temperatures and pressures for wall sizing. However, increasing the service life from $300,000 \mathrm{hr}$ to $500,000 \mathrm{hr}$ will decrease the allowable stress a roughly estimated $3-10 \%$ with a corresponding increase in wall thickness.

Also under consideration is the required wall thickness for the downstream piping for the same design conditions. For this case it is assumed that the piping will be constructed to commercial standards, e.g. 
B31.3. Several materials are considered; $9 \mathrm{Cr}-1 \mathrm{Mo}-\mathrm{V}, 800 \mathrm{H}, 316 \mathrm{SS}, 347 \mathrm{SS}$, Hastelloy $\mathrm{X}$ and 617. Although not all materials are listed in B31.3, i.e. 617 is not (Ref. 3); as discussed above, the use of Section VIII, Div 1 materials is also permitted for B31.3 construction. The following thickness estimates are based on the same approximate thickness formula with an assumed mean pipe radius of 8.0in.

\section{B31.3}

$$
\text { Design Conditions (1112F/3480psi) }
$$

Allowable stress $(\mathrm{ksi})$

$9 \mathrm{Cr}-1 \mathrm{Mo}-\mathrm{V}$

$800 \mathrm{H}$

$316 S S$

$347 S S$

Hastelloy X

617
9.0

11.0

11.8

13.3

16.7

20.8
Required thickness $\left(r_{m}=8.0 i n\right)$

1.58

1.47

1.31

1.04

0.84

\section{Summary}

The materials approved for construction under the rules of Section III, Subsection NH are very limited, five in all, as compared to the available materials under Section VIII, Div 1 which number in the hundreds. Although the allowable stress levels in $\mathrm{NH}$ are lower than those for Section VIII, Div 1, this is largely compensated by the use of service level operating temperatures and pressures in $\mathrm{NH}$ as opposed to the use of the somewhat higher design conditions in Section VIII, Div1. The biggest difference is in design rigor. For primary loadings which determine wall thickness, the $\mathrm{NH}$ time dependent allowable stress criteria are based on the actual design life whereas the allowable stresses for Section VIII, Div 1 in the creep regime are based on the properties at $100,000 \mathrm{hr}$. An even bigger difference in design rigor is the treatment of cyclic service. Section VIII, Div 1 doesn't require an evaluation of secondary or peak stresses that govern shakedown, fatigue and creep fatigue damage whereas explicit rules are provided in $\mathrm{NH}$ for these cycle life limiting phenomena. As shown by the example, at the specified design temperature and pressure, $600 \mathrm{C}$ and $24 \mathrm{MPa}$ respectively, $2.25 \mathrm{Cr}-1 \mathrm{Mo}$ is not a viable construction material, Alloy $800 \mathrm{H}$ is somewhat marginal, due primarily to the very high pressure over the large diameter. There is a clear incentive for 617 to be included in Section III, Subsection NH for such high pressure and large diameter applications.

Because the assumed diameter of the downstream piping is a factor of 5 smaller than the vessel diameter, the resulting wall thicknesses for a range of materials is also a factor of 5 smaller; thus significantly expanding the options for the piping material. 


\section{References}

(1) Jawad, M. H. and Jetter, R. I. "Design and Analysis of ASME Boiler and Pressure Vessel Components in the Creep Range" ASME Press, 2009

(2) "Companion Guide to the ASME Boiler and Pressure Vessel Code" Third Edition, K. R. Rao Editor, ASME Press, 2009

(3) Morton, D. K. personal communication 